Technical Report COO-1197-37

POINT DEFECTS IN IONIC CRYSTALS

AEC Contract AT(11-1)-1197

\title{
Fina1 Report
}

September 30, 1968

\section{LEGAL NOTICE}

This report was prepared as an account of Government sponsored work. Neither the United States, nor the Commission, nor any person acting on behalf of the Comonission:

A. Makes any warranty or representation, expressed or implled, with respect to the accuracy, completeness, or usefulness of the information contained in this report, or that the use of any information, apparatus, method, or process disclosed in thls report may not infringe privately owned rights; or

privately owned rights, or

B. Assumes any liabilities with respect to the use of, or for damages resulting from the se of any information, apparatus, method, or procesis disclosed in thls report.

As used in the above. "person acting on behalf of the Commission" includes any employee or contractor of the Commission, or employee of such contractor, to the extent that such employee or contractor of the Commission, or employee of such contractor prepares, disseminates, or provides accese to, any information pursuant to his employment or contract with the Commission, or his employment with guch contractor.$$
\text { - }
$$

to the

U. S. Atomic Energy Commission

by

Robert J. Friauf, Principal Investigator

University of Kansas, Lawrence, Kansas 


\section{DISCLAIMER}

This report was prepared as an account of work sponsored by an agency of the United States Government. Neither the United States Government nor any agency Thereof, nor any of their employees, makes any warranty, express or implied, or assumes any legal liability or responsibility for the accuracy, completeness, or usefulness of any information, apparatus, product, or process disclosed, or represents that its use would not infringe privately owned rights. Reference herein to any specific commercial product, process, or service by trade name, trademark, manufacturer, or otherwise does not necessarily constitute or imply its endorsement, recommendation, or favoring by the United States Government or any agency thereof. The views and opinions of authors expressed herein do not necessarily state or reflect those of the United States Government or any agency thereof. 


\section{DISCLAIMER}

Portions of this document may be illegible in electronic image products. Images are produced from the best available original document. 


\section{INTRODUCTION}

The primary interest of this research has been directed toward two distinct, but related, types of point defects in ionic crystals. One area has been the study of atomic transport mechanisms for ions. This has involved experimental measurements of ionic conductivity and diffusion in alkali, silver, and thallium halides, and interpretation of the results with the use of theories of defect formation and association and of correlation factors for diffusion. The other area has been the study of electrons trapped at color centers in alkali halides. This has involved experimental measurements of optical absorption, photoconductivity, and electron spin resonance, and development of a detailed theory of electron wavefunctions for $F$ centers. The following report is arranged according to this general outline.

Two appendices provide a summary of the research effort. The first is a list of technical reports arranged in four categories: (A) articles in scientific journals, (B) abstracts of papers presented at scientific meetings, (C) unpublished technical reports, and (D) contract reports. The unnumbered reports in categories (A) and (C) represent anticipated future reports based, at least in part, on effort supported by this contract. References to the reports are given as appropriate at the end of each paragraph. The second appendix is a list of personnel divided into two categories: (A) professional and (B) graduate students. The indicated effort includes both University and Contract Support.

\section{DIFFUSION AND IONIC CONDUCTIVITY}

\section{(1) Facilities}

During diffusion measurements it is necessary to monitor the sample temperature over long periods of time. This was originally done by taking manual readings of thermocouple e.m.f. with a potentiometer. The procedure has now been completely automated with the output of a digital voltmeter and digital clock being recorded directly on punched cards. The data from these cards is then processed by a computer program to yield the effective time for diffusion. A voltage calibration circuit has also been developed to permit calibration of the digital voltmeter on all ranges against a standard cell.

For the measurements of ionic conductivity it is advantageous to use audio frequencies in the reange 0.1 to $100 \mathrm{kHz}$ in order to avoid polarization effects at the electrodes. An improved circuit for connecting decade resistors to minimize errors at high frequency and resistance has been designed and constructed, and recently a more sensitive capacitance bridge has been obtained and installed.

One of the important new experimental techniques has been the measurement of tracer diffusion in an applied electric field. Since the samples have an appreciable ionic conductivity, it is necessary to sustain a dc current through the sample in order to maintain the electric field. 
For this purpose a moderately high voltage, high current source $(300 \mathrm{v}$, $300 \mathrm{ma}$ ) has been constructed, along with a silver coulometer to measure the integrated current.

For all of the experimental work it has been necessary to use single crystals. Commercial sources have not been very satisfactory, both because nominally pure crystals often contain appreciable amounts of impurities and because doped crystals are usually not readily available. Silver and thallium halides have been grown in evacuated, sealed off quartz tubes, but this method has not been feasible for alkali halides. Hence a crystal growing furnace was constructed to allow growth of alkali halide crystals in a controlled atmosphere. This precaution is often vital to avoid incorporation of $\mathrm{OH}^{-}$or $\mathrm{O}^{2-}$ ions in the crystals. The same motor and gear arrangement can be used either for pulling alkali halide crystals from the melt or lowering. the quartz tubes through a temperature gradient for the silver and thallium halides. [COO-1197-19]

\section{(2) Silver Halides}

The first effort was devoted to careful measurements of diffusion and ionic conductivity in pure $\mathrm{AgCl}$ in order to separate the contributions of collinear and non-collinear interstitialcy motion for the diffusion of $\mathrm{Ag}$. At first it was not possible to obtain a satisfactory interpretation of the results, but the difficulty was removed when newer data on the relative mobility of interstitial and vacancy motion became available. This feature indicated the importance of including Debye-Hückel interactions in the treatment of ionic conductivity data in the silver halides and suggested re-examination of the previous calculations for $\mathrm{AgBr}$. The final publication, therefore, provides the most recent and reliable information on the mobilities (or jump frequencies) for the two types of interstitialcy motion in the silver halides. [C00-1197-1, 12, 22]

Another set of measurements on diffusion in $\mathrm{AgCl}: \mathrm{Cd}$ provided an opportunity for an accurate check of the experimental procedures used for comparing tracer diffusion to ionic conductivity. This was desirable because of the uncertainty mentioned above and because of small but tantalizing indications from measurements on $\mathrm{NaCl}$ and $\mathrm{TICl}$ (discussed below). The theoretical value of $f_{v}=0.78146$ was we11-known for diffusion by single vacancies on a fcc lattice; the difficulty was obtaining an experimental system in which it was known unambiguously that all of the diffusion and ionic conductivity was occurring by motion of single vacancies. The most suitable system seemed to be $\mathrm{AgCl}$ : Cd at moderate temperatures, in which nearly all of the interstitial silver ions are suppressed by the divalent cadmium, leaving only silver ion vacancies. After small corrections for concentration gradients and for residual interstitial ions, the experimental results did agree with the theoretical value within 1 per cent. Thus not only was the theory of correlation factors confirmed (of which there was not much doubt), but more imprtantly the absolute accuracy of the comparison of ionic conductivity and diffusion was established as a basis for interpretation of other experiments. [C00-1197-18, 21, 24] 
An intriguing problem for many years has been a large, anomalous increase in the ionic conductivity of both $\mathrm{AgCl}$ and $\mathrm{AgBr}$ in the temperature region of about $100^{\circ} \mathrm{C}$ below the melting points. It is believed that this is due to a lowering of the formation energy for Frenkel defects through Debye-Hückel type interactions because of the rather large concentration of defects ( 0.1 and 1 per cent at the melting point for $\mathrm{AgCl}$ and $\mathrm{AgBr}$, respectively). An accurate theory for this effect has been developed by K. L. Kliewer and R. Sevenich at Iowa State University, and they have expressed an interest in obtaining experimental data to test the theory. Hence an experimental program has been under way for the past year and will continue this year to obtain accurate, closely-spaced measurements of ionic conductivity vs. temperature for the high temperature region of $\mathrm{AgCl}$. The principal experimental problems seem to be obtaining good electrode contact (attempts with evaporated silver and colliodal graphite), accurate measurement of the conductivity (new capacitance bridge), calibration of the thermocouple at fixed temperature points (in progress), and calibration of the digital voltmeter (voltage calibration circuit). These results, in conjunction with the theory, will provide an important extension of the understanding of the formation of defects in ionic crystals. [unnumbered reports by Aboagye and by Aboagye, Valge, Holmberg, and Friauf]

\section{(3) Alkali Halides}

At one time it was thought that single cation vacancies were the predominant defect for intrinsic ionic conductivity and cation diffusion. If this were true, it should be possible to obtain a direct comparison of the two phenomena through the Einstein relation along with the correlation factor $f_{v}$. Since this had never been done with any real accuracy, we initiated diffusion measurements of $\mathrm{Na}$ in $\mathrm{NaCl}$ for this purpose. After correction for anion diffusion the first results showed a 10 to 15 per cent excess diffusion that could not be accounted for from the ionic conductivity. This suggested a contribution to diffusion of $\mathrm{Na}$ by neutral vacancy pairs, but experimental problems with conductivity measurements made a quantitative analysis infeasible at the time. These results, however, along with other indications of vacancy pair contributions from anion diffusion in doped crystals, provided the impetus for the more extended experiments below. $[\mathrm{COO}-1197-6,9,33]$

There are two major problems for a more general interpretation of diffusion processes in the alkali halides: one is separating the single vacancy and vacancy pair contributions for both cations and anions, and the other is separating the cation and anion contributions to the conductivity. Usually only three types of data have been available: diffusion of cation tracers, diffusion of anion tracers, and measurement of total ionic conductivity. Since the traditional transport number measurements of Tubandt appear to be inherently untrustworthy, an additional kind of measurement is needed. This is why we have measured tracer diffusion with an applied electric field: the charged single vacancies should drift along the electric field and produce a corresponding shift of the diffusion profile, whereas the diffusion of the neutral vacancy pairs should not be influenced by the field. In order to make the technique feasible, it has been necessary to show how to obtain a solution of the diffusion equation even when the field varies with time; this is accomplished by relating the time integral of the field to the total charge passing through the sample. In addition it has 
been helpful for analyzing diffusion profiles to obtain an analytical solution of the diffusion equation with a barrier at the interface between two samples. The experimental problems of ensuring a good contact at the interface have been only partially overcome, and some difficulties remain with deterioration of the samples near the electrodes, sometimes extending into the diffusion region, and with possible variation of the electric field with position. Despite these difficulties a direct experimental check at two temperatures shows that the tracer drift mobility measurements with this technique are reliable to better than 15 per cent. [C00-1197-26, 27]

The interpretation of the diffusion experiments in a field has required clarification of the concept of tracer drift mobility. With this interpretation the results indicate that vacancy pairs do make an appreciable contribution to cation diffusion (nearly 40 per cent at the melting point). The comparison with the vacancy pair contribution to anion diffusion is consistent with the general theory of vacancy pair diffusion, but comparison to previously reported high frequency dielectric loss measurements in $\mathrm{NaCl}$ leads to an unresolvable discrepancy (recent results show that the dielectric loss measurements are probably not ascribable to vacancy pairs in any case). The activation energies for cation diffusion by both single vacancies and vacancy pairs are noticably larger than previous values and indicate in both cases that modifications in the theoretical calculations of these energies may be necessary. It was also necessary to examine the possible contributions of cation Frenkel defects and of vacancy triplets in order to show that the experimental check of the tracer drift mobility experiments is independent of the type of defect mechanism. In summary the pioneering use of this new experimental technique has contributed to a much more complete and sophisticated understanding of ionic transport processes in Nac1. [COO-1197-30, 32]

\section{(4) Thallium Halides}

Extensive experimental measurements have been made of ionic conductivity and diffusion in TIC1. The measured conductivity is appreciably larger than that reported in the older literature, but a possible electronic contribution seems to be ruled out by consideration of polarization effects, general temperature dependence, and reproducibility of results. Nevertheless the sum of cation and anion diffusion coefficients gives an excess diffusion of 10 to 15 per cent more than can be accounted for from the ionic conductivity. [COO-1197-9]

There appear to be two possible explanations for the excess diffusion. One is contributions from vacancy pairs, as. for $\mathrm{NaCl}$. The other is that there can be jumps from next nearest neighbors as well as nearest neighbors into a single vacancy because of the more open s.c. structure of T1C1. Theoretical correlation factors have been calculated for both possibilities, and either one could provide a suitable explanation. There is perhaps a slight preference for the second explanation, but additional diffusion measurements 'on doped samples and with an electric field will be required to provide a complete understanding. [C00-1197-35 and unnumbered report by Friauf] 


\section{(5) Theory of Diffusion and Correlation Factors}

The experimental test of the correlation factor for single vacancies required diffusion of $\mathrm{Ag}$ in $\mathrm{AgCl}$ containing divalent $\mathrm{Cd}$. In order to ensure that there was no contribution to diffusion of Ag by vacancies complexed with Cd ions, it was necessary to understand the theory of diffusion of divalent ions in ionic crystals. A review of the literature showed that there is a complete, formal theory by R. Howard and A. B. Lidiard, but also revealed that there have been many incorrect applications of this theory. Hence a paper was written to present the general results of the theory from the experimental viewpoint and to provide critical comments about the application of the theory to a number of experimental arrangements for the alkali halides. The analysis of the results for AgCl provided the needed information for the test of the correlation factor and suggested an explanation for an apparent change of diffusion mechanism at intermediate temperatures. The analysis of the results for $\mathrm{AgBr}$ seems to remove the necessity for making a very peculiar assumption about an increase in mobility of silver ion vacancies with an increase in divalent ion concentration. Thus this work has not only provided the desired information for interpreting diffusion in $\mathrm{AgCl}$ :Cd but has also clarified a number of other problems. $[\mathrm{COO}-1197-25,36]$

The experimental results for both $\mathrm{NaCl}$ and $\mathrm{T} 1 \mathrm{Cl}$ have suggested contributions to diffusion by vacancy pairs. As long as the vacancy pairs remain bound, the relative contributions to cation and to anion diffusion are determined, in a rather complicated way, by the relative jump frequencies of cations and of anions into the vacancy pair. In order to make comparisons to experimental results, therefore, it has been necessary to examine the theory of correlation factors for diffusion by vacancy pairs. Although much of the basic theory has been done by other persons, it has still been advantageous to reformulate the results in several ways that are particularly appropriate for making experimental comparisons. It has also been necessary to work out the atomic theory of dielectric loss measurements for vacancy pairs in order to try to compare these measurements to the diffusion resilts. A11 of these aspects have been particularly important for interpreting the results in $\mathrm{NaCl}$ and are summarized in the paper describing those results. $[\mathrm{COO}-1197-7,32]$

The experimental results for TICl have suggested two new kinds of diffusion mechanisms, vacancy pairs on a s.c. lattice and mixed nearest and next nearest neighbor jumps into single vacancies. In developing a general procedure for calculating the needed correlation factors for these mechanisms, a method has been found for obtaining an exact expression for the sum of the infinite series arising from correlation between non-consecutive jumps of the tracer. The method is somewhat similar to a treatment published independently by $R$. Howard, but some differences also remain. Computer calculations are then used for obtaining the correlation factor for the first return of the diffusing entity to the tracer. Some results have already been obtained for the mixed vacancy jumps in T1C1, and calculations are continuing for the vacancy pair diffusion. [COO-1197-28, 35 and unnumbered report by Friauf] 
Summary

Diffusion of $\mathrm{Ag}$ in $\mathrm{AgCl}$ has yielded quantitative data on collinear and non-collinear interstitialcy motion, and has also provided an absolute test of the comparison of diffusion and ionic conductivity measurements as a basis for interpreting other experiments of this type. Diffusion of Na in $\mathrm{NaCl}$ has first suggested a contribution from vacancy pairs, and application of the new experimental technique of tracer diffusion in an electric field has given a better understanding of all ionic transport processes, in addition to quantitative results for cation diffusion by single vacancies and by vacancy pairs. Diffusion of $\mathrm{T} 1$ and $\mathrm{Cl}$ in $\mathrm{T} 1 \mathrm{Cl}$ has confirmed the basic picture of diffusion by single vacancies with some additional diffusion by either vacancy pairs or next nearest neighbor jumps. The necessary theory for the formulation and interpretation of these experiments has been developed, considerable clarification has been provided for the application of the theory of diffusion by divalent ions, and a general method has been devised for calculating correlation coefficients for the proposed new diffusion mechanisms in TIC1.

\section{COLOR CENTERS}

\section{(1) Facilities}

The original observation of color centers was by optical absorption, and this method is still important for identifying centers and determining the relative amounts of different kinds of centers in the crystal. For this purpose a Perkin-Elmer spectrophotometer was obtained and installed, and several small dewars were fabricated to permit measurements at liquid nitrogen temperature. A number of polarizing prisms and depolarizers were obtained and mounted for polarized bleaching and absorption experiments.

For photoconductivity experiments a stainless steel helium dewar was purchased and mounted on tracks to provide ready access for sample mounting and insertion into the spectrophotometer. A dynamic capacitor electrometer was installed to measure the very small currents, with particular attention paid to electrostatic shielding, leakage resistance, and minimization of capacitance for the input to the pre-amplifier unit. A stereo camera shutter was installed in the spectrophotometer to permit short light pulses for photoconductivity measurements.

Originally an X-band electron spin resonance (ESR) spectrometer was assembled, with all electronics constructed locally. Since attempts to modify this spectrometer for ENDOR measurements were unsuccessful, a commercial ESR spectrometer and magnet system were obtained (with other funds), and the new system is now giving excellent sensitivity for both ESR and ENDOR.

The crystal growing furnace described earlier is also used to grow alkali halide crystals, both pure and doped, for color center experiments. An Inconel bomb has been constructed for additive coloring, and with the help of an oil manometer the density of color centers produced can be conveniently controlled. A small monochromator provides light of selected wavelength for causing bleaching and optical transformations of color centers. 


\section{(2) Optical Absorption}

It has been known for many years that colored $\mathrm{Li} F$ crystals often contain an absorption band at $222 \mathrm{~nm}$ in addition to the prominent $\mathrm{F}$ band at $250 \mathrm{~nm}$. We were able to produce and study the $222 \mathrm{~nm}$ band by coloring with neutron irradiation at $300^{\circ} \mathrm{C}$. By correlating the height of the band with the amount of $\mathrm{Mg}$ doping, we were able to show unambiguously that the $222 \mathrm{~nm}$ band is associated with the presence of magnesium, and it was proposed that this may be similar to the $\mathrm{Z}$ bands in $\mathrm{KCl}: \mathrm{Sr}$, for instance. Broad bands were also observed at 320 and $350 \mathrm{~nm}$, and it was proposed that these are $\mathrm{F}_{2}$-bands that are stabilized in some way by proximity to magnesium. $[\mathrm{COO}-1197-5]$

Several experiments were attempted to produce polarized bleaching of $\mathrm{z}_{1}$ and $\mathrm{z}_{2}$ bands in $\mathrm{KCl}: \mathrm{Sr}, \mathrm{KCl}: \mathrm{Ca}$ and $\mathrm{NaCl}: \mathrm{Ca}$. Unfortunately no significant effects were obtained, in agreement with the experience of other workers in this field. Some additional broad absorption was observed near the $\mathrm{F}$ band in $\mathrm{NaCl}: \mathrm{Ca}$, but it was not possible to identify separate $\mathrm{Z}$ bands. An indication of $L$ bands was obtained during preliminary experiments in $\mathrm{NaCl}$, but the results were not confirmed because of changes in personnel. [COO-1197-10]

Radiation chemists have studied trapped electrons in glass-like alkaline ices formed by rapid freezing of aqueous solutions of $\mathrm{NaOH}$, for instance. First reports showed an optical absorption band at $585 \mathrm{~nm}$, and the presumably F-like nature of this band was confirmed by ESR measurements. On prolonged gamma irradiation, however, it was observed that both the optical absorption and ESR signals disappeared, and we therefore suspected the formation of dielectron centers, with two trapped electrons in a singlet state, similar to F'centers in alkali halides. We observed a very broad optical absorption in the near infrared with a maximum near $1000 \mathrm{~nm}$ and were able to show reasonable correlation between the increase of this band and the decrease of the $\mathrm{F}$ band by either prolonged irradiation or optical bleaching. [COO-1197-29]

Optical absorption measurements have also been an integral part, of course, of the photoconductivity and ESR experiments described below.

\section{(3) Photoconductivity}

Measurements have recently been completed for $z_{1}, z_{2}$, and $z_{3}$ bands in $\mathrm{KCl}: \mathrm{Sr}$. This represents an extension of much earlier work of similar nature in this laboratory; experimental techniques have been improved considerably both in obtaining a much more nearly complete conversion of $F$ to $z_{1}$ and $z_{2}$ centers and in the improved electrometer arrangements. It is known from many experiments that all of the $Z$ bands are definitely associated with the presence of the divalent ion, but no definite models have been established. Early models proposed that $Z_{3}$ centers were formed by adding an electron to $z_{2}$ centers, whereas later models propose that $z_{3}$ centers are formed by removing an electron from $z_{2}$ centers.

The photoconductivity results for $\mathrm{z}_{2}$ show a behavior qualitatively similar to $\mathrm{F}$ centers: low quantum efficiency at $-180^{\circ} \mathrm{C}$ rising to unity near $-100^{\circ} \mathrm{C}$ (compared to $-130^{\circ} \mathrm{C}$ for $\mathrm{F}$ centers); these results give an activation energy of about $0.1 \mathrm{eV}$ from the relaxed excited state to the 
conduction band. The $Z_{3}$ centers show no photoconductivity at all (quantum efficiency zero) throughout the temperature range $\left(-180^{\circ}\right.$ to $-100^{\circ} \mathrm{C}$ ) where they are stable; this behavior indicates a much more tightly bound relaxed excited state than for $\mathrm{z}_{2}$ centers and confirms the newer proposal for the relationship between $z_{2}$ and $z_{3}$ centers. The raw data for $z_{1}$ centers give a small quantum efficiency at room temperature (approximately one-third in agreement with earlier results) and suggest a fairly rapid decrease at lower temperatures. [Unnumbered reports by Renneke and by Renneke and Friauf]

Throughout these experiments control measurements have been made on pure $\mathrm{KCl}$ crystals containing $\mathrm{F}$ centers, and there continue to be tantalizing indications of non-uniform quantum efficiency for different wavelengths within the general range of $\mathrm{F}$ absorption. These results are probably associated with underlying absorption to higher excited states of $M$ and perhaps $R$ centers, and accurate photoconductivity measurements would give interesting information about the relaxed excited states of these centers. There are also intriguing questionsabout the behavior of photoconductivity for the higher energy regions of the $\mathrm{K}$ band. It is contemplated that work will continue in these areas.

\section{(4) ESR and ENDOR}

The first ESR results were obtained for $Z_{1}$ centers in $\mathrm{KCl}: \mathrm{Sr}$. These showed a broad, isotropic ESR absorption with no resolved hyperfine structure, with the same g-value as $F$ centers but with a slightly larger width. Although no definite correlation could be made with an atomic model, simple perturbation calculations showed that the results were not inconsistent with proposed models. A somewhat different ESR band was obtained after thermal ageing at room temperature, with detectable changes in both g-value and width. This was tentatively ascribed to $z_{2}$ centers, but more recent results of other workers have cast some doubt on this assignment; the matter appears to be still an open question. [COO-1197-2,3]

Subsequent attempts to obtain ENDOR spectra were unsuccessful for some time, but a new experimental system is now yielding good results. With the improved conversion of $F$ to $z_{1}$ and $z_{2}$ centers it will be possible in the near future to examine the question of $\mathrm{z}_{2}$ center resonance; the more positive identification of ENDOR spectra will eliminate possible confusion or oversight in comparison to a small signal from residual $F$ centers. Other work is in progress in cooperation with the University of Missouri and Oak Ridge National Laboratory to investigate ENDOR spectra of $F$ centers in $\mathrm{BaO}$ and BaS.

\section{(5) Theory of $F$ Center Wavefunctions}

The original impetus was provided by a desire to understand and explain the hyperfine interaction constants obtained for $F$ and $z_{1}$ centers from ESR and ENDOR experiments. For this purpose a rather detailed treatment of the ground state of the $F$ center is required, and it was considered to be paramount to treat the atomic environment with some realism. For this purpose the pseudopotential approach of Cohen and Heine was introduced for the neighboring ions, marking the first use of this method in color center calculations. Two other new features of this work were the expansion of 
the crystal field in Kubic harmonics and a somewhat novel use of perturbation theory to determine the first order correction to the wavefunction. The results pointed out obvious shortcomings of the point ion potential, particularly when nonspherical terms in the crystal potential are considered, and provided an improved estimate of the location of the ground state of the $F$ center with respect to the conduction band.

$[\mathrm{COO}-1197-11,13,15,16]$

This work was continued in order to incorporate additional features. Some of these were inclusion of exchange with the Slater approximation, consideration of relaxation of the nearest neighbor ions, and phenomenological treatment of interaction with lattice vibrations. The problems of calculating spin-orbit splittings, oscillator strengths, and hyperfine interactions for wavefunctions of cubic rather than spherical symmetry were formulated exactly, with full use of group theory, and an improved method of calculating overlap integrals was introduced. The numerical results show some improvement in agreement with experimental values. Even more significant, however, is the indication that lattice distortion may make major changes in the $F$ center wavefunction and that even small nonspherical parts of the wavefunction (5-10 per cent) lead to large changes (50 to 100 per cent) in computed values of oscillator strength, spin-orbit splitting, etc. [COO-1197-20,31, 34 and unnumbered reports by Taylor and Friauf]

There are still many problems that remain to be considered from this point of view. Among the physical problems are better treatment of lattice relaxations, improvement of free ion wavefunctions for use in crystals, and incorporation of dynamic electronic polarization. Other interesting centers that may be considered are $\mathrm{F}_{\mathrm{A}}$ centers, and $\mathrm{U}_{2}$ centers. Treatment of centers with appreciably lower symetry, such as $M$ and $R$ centers, will require appreciable modification of the expansion techniques.

Summary

The optical absorption experiments have identified bands associated with $\mathrm{Mg}$ in $\mathrm{Li} \mathrm{F}$ and with trapped dielectrons in alkaline ice, and have also been a basic part of other experiments. The photoconductivity measurements have helped to substantiate an important feature of the recently proposed models for $z_{2}$ and $z_{3}$ centers in $K C 1: S r$ and promise to give useful information about higher excited states from $M$ centers and in the $\mathrm{K}$ band region. The early ESR measurements suggested some features for $\mathrm{Z}_{1}$ and $\mathrm{z}_{2}$ centers in $\mathrm{KCl}: \mathrm{Sr}$, and the present ENDOR apparatus should permit further study of $z_{1}, z_{2}$, and $z_{3}$ centers as we11 as investigation of $\mathrm{F}$ centers in $\mathrm{BaO}$ and $\mathrm{BaS}$. The theoretical work has introduced the use of pseudopotentials and nonspherical crystal fields into color center calculations, has thereby pointed out the inherent deficiencies of the point ion potential, and promises to provide a fruitful way of treating many aspects of the interaction between the trapped electron and the surrounding ion cores in some detail. 
LIST OF REPORTS

(A) Articles in Scientific Journals

\begin{tabular}{|c|c|c|}
\hline $\begin{array}{l}\text { COO-1197- } 1 \\
\text { June, } 1962\end{array}$ & R.J. Friauf & $\begin{array}{l}\text { "Ionic Transport Processes in the Silver } \\
\text { Halides," J. Phys. Chem. 66, 2380-2383 } \\
(1962) \text {. }\end{array}$ \\
\hline $\begin{array}{l}\text { COO-1197- } 3 \\
\text { Dec., } 1962\end{array}$ & $\begin{array}{l}\text { G.E. Conklin } \\
\text { and R.J. Friauf }\end{array}$ & $\begin{array}{l}\text { "Electron Spin Resonance of the } \mathrm{z}_{1} \text { Band } \\
\text { in KC1 with } \mathrm{SrCl}_{2} \text {," Phys. Rev. } 132 \text {, } \\
189-194 \text { (1963). }\end{array}$ \\
\hline $\begin{array}{l}\text { Coo-1197- } 5 \\
\text { Apr., } 1963\end{array}$ & $\begin{array}{l}\text { F. Pilcher, } \\
\text { D. Schinke, } \\
\text { and R.J. Friauf }\end{array}$ & $\begin{array}{l}\text { "Optical Absorption of Color Centers in } \\
\text { Lithium Fluoride Containing Magnesium } \\
\text { Additive," J. Phys. Chem. Solids 24, } \\
1687-1691 \text { (1963). }\end{array}$ \\
\hline $\begin{array}{l}\text { CoO-1197-15 } \\
\text { May, } 1965\end{array}$ & $\begin{array}{l}\text { J. Kuebler } \\
\text { and R.J. Friauf }\end{array}$ & $\begin{array}{l}\text { "Perturbation Calculations of F-Center } \\
\text { Wavefunctions with Point Ion and Pseudo- } \\
\text { potentials," Phys. Rev. 140, A1742- } \\
\text { A1753 (1965). }\end{array}$ \\
\hline $\begin{array}{l}\text { CoO-1197-22 } \\
\text { Feb., } 1967\end{array}$ & $\begin{array}{l}\text { M.D. Weber } \\
\text { and R.J. Friauf }\end{array}$ & $\begin{array}{l}\text { "Interstitialcy Motion in the Silver } \\
\text { Halides," J. Phys. Chem. Solids } \underline{29} \text {, } \\
\text { Xxxx (1968). }\end{array}$ \\
\hline $\begin{array}{l}\text { Coo-1197-24 } \\
\text { May, } 1968\end{array}$ & $\begin{array}{l}\text { J. Gracey } \\
\text { and R.J. Friauf }\end{array}$ & $\begin{array}{l}\text { "Experimental Verification of the } \\
\text { Correlation Factor for Vacancy Diffusion } \\
\text { in Silver Chloride," J. Phys. Chem. } \\
\text { Solids 29, YYYY (1968). }\end{array}$ \\
\hline $\begin{array}{l}\text { COO-1197-25 } \\
\text { May, } 1968\end{array}$ & R.J. Friauf & $\begin{array}{l}\text { "Comments on Diffusion by Divalent Ions } \\
\text { in Alkali and Silver Halides," J. Phys. } \\
\text { Chem. Solids 29, ZZZZ (1968). }\end{array}$ \\
\hline $\begin{array}{l}\text { Coo-1197-29 } \\
\text { Jan., } 1968\end{array}$ & $\begin{array}{l}\text { L. Kevan, } \\
\text { D.R. Renneke, } \\
\text { and R.J. Friauf }\end{array}$ & $\begin{array}{l}\text { "Optical Absorption Spectrum of Trapped } \\
\text { Dielectrons in Alkaline Ice," Solid State } \\
\text { Communications } 6,469-471 \text { (1968). }\end{array}$ \\
\hline $\begin{array}{l}\text { COO-1197-32 } \\
\text { Aug. , } 1968\end{array}$ & $\begin{array}{l}\text { V.C. Nelson } \\
\text { and R.J. Friauf }\end{array}$ & $\begin{array}{l}\text { "Diffusion of Vacancies and Vacancy Pairs } \\
\text { in } \mathrm{NaCl} \text {," submitted to J. Phys. Chem. Solids. }\end{array}$ \\
\hline $\begin{array}{l}\text { CoO-1197-33 } \\
\text { Aug., } 1968\end{array}$ & $\begin{array}{l}\text { H.L. Downing } \\
\text { and R.J. Friauf }\end{array}$ & $\begin{array}{l}\text { "Self-Diffusion of } \mathrm{Na} \text { in NaĊl," submitted } \\
\text { to J. Phys. Chem. Solids. }\end{array}$ \\
\hline Feb., 1969 & $\begin{array}{l}\text { L. Taylor } \\
\text { and R.J. Friauf }\end{array}$ & $\begin{array}{l}\text { "Effect of Crystal Fields, Slater Exchange, } \\
\text { and Lattice Distortion on F Center Wave } \\
\text { Functions" }\end{array}$ \\
\hline Feb., 1969 & $\begin{array}{l}\text { L. Taylor } \\
\text { and R.J. Friauf }\end{array}$ & $\begin{array}{l}\text { "Calculation of Spin-Orbit, Hyperfine, } \\
\text { and Electric Quadrupole Splittings for. } \\
\text { F Centers in KC1, CsF, and MgO" }\end{array}$ \\
\hline Feb., 1969 & $\begin{array}{l}\text { L. Taylor } \\
\text { and R.J. Friauf }\end{array}$ & $\begin{array}{l}\text { "Interaction of Lattice Vibrations with } \\
\text { F Centers in } \mathrm{KCl}, \mathrm{CsF} \text {, and } \mathrm{MgO} "\end{array}$ \\
\hline
\end{tabular}




\begin{tabular}{|c|c|c|}
\hline Mar., 1969 & R.J. Friauf & "Diffusion Processes in T1C1" \\
\hline Mar., 1969 & R.J. Friauf & $\begin{array}{l}\text { "Calculation of Correlation Factors for } \\
\text { Diffusion in Cubic Crystals" }\end{array}$ \\
\hline Apr., 1969 & $\begin{array}{l}\text { D.R. Renneke } \\
\text { and R.J. Friauf }\end{array}$ & $\begin{array}{l}\text { "Photoconductivity of } \mathrm{z}_{1}, \mathrm{z}_{2} \text {, and } \mathrm{z}_{3} \\
\text { Centers in KCl:Sr" }\end{array}$ \\
\hline May, 1969 & $\begin{array}{l}\text { J. Aboagye, } \\
\text { L. Valge, G. Holmberg, } \\
\text { and R.J. Friauf }\end{array}$ & $\begin{array}{l}\text { "High Temperature Ionic Conductivity } \\
\text { of AgCl" }\end{array}$ \\
\hline
\end{tabular}

(B) Abstracts of Papers Presented at Scientific Meetings

\begin{tabular}{|c|c|}
\hline $\begin{array}{l}\text { CoO-1197- } 2 \\
\text { Aug., } 1962\end{array}$ & $\begin{array}{l}\text { R.J. Friauf, } \\
\text { G.E. Conklin, } \\
\text { and D.L. Foster }\end{array}$ \\
\hline $\begin{array}{l}\text { COO-1197- } 6 \\
\text { Apr., } 1963\end{array}$ & R.J. Friauf \\
\hline $\begin{array}{l}\text { Coo-1197-7 } \\
\text { Aug. , } 1963\end{array}$ & R.J. Friauf \\
\hline $\begin{array}{l}\text { CoO-1197-13 } \\
\text { Jan., } 1965\end{array}$ & $\begin{array}{l}\text { R.J. Friauf } \\
\text { and J. Kuebler }\end{array}$ \\
\hline $\begin{array}{l}\text { Coo-1197-16 } \\
\text { May, } 1965\end{array}$ & $\begin{array}{l}\text { J. Kuebler, } \\
\text { L. Taylor, } \\
\text { and R.J. Friauf }\end{array}$ \\
\hline $\begin{array}{l}\text { CoO-1197-20 } \\
\text { Jan., } 1967\end{array}$ & $\begin{array}{l}\text { L. Taylor } \\
\text { and R.J. Friauf }\end{array}$ \\
\hline $\begin{array}{l}\text { COO-1197-21 } \\
\text { Jan. , } 1967\end{array}$ & $\begin{array}{l}\text { R.J. Friauf } \\
\text { and.J. Gracey }\end{array}$ \\
\hline $\begin{array}{l}\text { COO-1197-27 } \\
\text { Oct., } 1967\end{array}$ & $\begin{array}{l}\text { R.J. Friauf } \\
\text { and V.C. Nelson }\end{array}$ \\
\hline
\end{tabular}

"Hyperfine Interactions of $z_{1}$ Centers in $\mathrm{KCl}: \mathrm{Sr}, "$ International Symposium on Color Centers in Alkali Halides, Stuttgart, Germany (1962).

"Ionic Transport Processes in Ionic Crystals," J. Electrochem. Soc. 110, 66C (1963).

"Diffusion and Correlation Effects in T1C1 and AgC1," Gordon Research Conference, Meriden, New Hampshire (1963).

"Calculation of F-Center Wavefunctions with Point-Ion and Pseudopotentials," Bul1. Am. Phys. Soc. II, 10, 306 (1965). "Pseudopotential Calculations for F Centers," International Symposium for Color Centers Alkali Halides, Urbana, Illinois (1965). "Crystal Field Effects on the $1 S$ and $2 P$ States of a Localized Center in a Cubic Potential," Bu11. Am. Phys. Soc. II, 12, 279 (1967).

"Experimental Verification of the Correlation Factor for Vacancy Diffusion," Bul1. Am. Phys. Soc. II, $\underline{12}, 326$ (1967). "Diffusion of Sodium in Sodium Chloride in an Applied Electric Field," in Mass Transport in oxides, edited by J. B. Wachtman, $\mathrm{Jr}$. and A. D. Franklin, National Bureau of Standards Special Publication 296, Washington, D.C. (1968), p. 9.

C00-1197-28 R.J. Friauf "Correlation Factor for Self-Diffusion by Mixed Vacancy Jumps," Bull. Am. Phys. Soc. II.., 13, 489 (1968). 
C0O-1197-30

June, 1968

C00-1197-31

June, 1968

C00-1197-35

Aug. , 1968

C00-1197-36

Aug. , 1968
V.C. Nelson

and R.J. Friauf

I.H. Taylor

and R.J. Friauf

R.J. Friauf

R.J. Friauf
"Diffusion of Vacancies and Vacancy Pairs in $\mathrm{NaCl}, "$ International Symposium on Color Centers in Alkali Halides, Rome, Italy (1968).

"Crystal Field Effects on F Center

Wavefunctions in $\mathrm{KCl}, \mathrm{CsF}$, and $\mathrm{MgO}$,"

International Symposium on Color Centers in Alkali Halides, Rome, Italy (1968).

"Diffusion in T1C1 and Calculation of Correlation Factors," International Conference on Science and Technology of Non-metallic Crystals, New Delhi, India (1969).

"Comments on Diffusion of Divalent Ions in AIkali and Silver Halides, "International Conference on Science and Technology of Non-metallic Crystals, New Delhi, India (1969).

(C) Technical Reports, Unpublished

\begin{tabular}{|c|c|}
\hline $\begin{array}{l}\text { Coo-1197- } 9 \\
\text { June, } 1964\end{array}$ & H. Downing \\
\hline $\begin{array}{l}\text { Coo-1197-10 } \\
\text { Aug., } 1964\end{array}$ & D. Lauer \\
\hline $\begin{array}{l}\text { COO-1197-11 } \\
\text { Dec., } 1964\end{array}$ & J. Kuebler \\
\hline $\begin{array}{l}\text { CO0-1197-12 } \\
\text { Dec., } 1964\end{array}$ & M. Weber \\
\hline $\begin{array}{l}\text { COO-1197-18 } \\
\text { Jan., } 1967\end{array}$ & J. Gracey \\
\hline $\begin{array}{l}\text { COO-1197-19 } \\
\text { Jan., } 1967\end{array}$ & R. Mellott \\
\hline $\begin{array}{l}\text { COO-1197-26 } \\
\text { Aug., } 1967\end{array}$ & V.C. Nelson \\
\hline $\mathrm{COO}-1197-34$ & L.H. Taylor \\
\hline Aug., 1967 & \\
\hline Feb., 1969 & D.R. Renneke \\
\hline May, 1969 & J. Aboagye \\
\hline
\end{tabular}

"Self-Diffusion of the Sodium Ion in Pure NaCl"

"Polarized Absorption Measurements of $\mathrm{NaCl}$ with $\mathrm{Ca}$ Impurity"

"Wave Function Calculations for F Centers in $\mathrm{NaCl}, \mathrm{KC} 1$, and $\mathrm{NaF}^{\prime}$

"Se1f-Diffusion of the Silver Ion in Pure AgC1"

"Experimental Verification of the Correlation Factor for Vacancy Diffusion in Silver Chloride"

"A Controlled Atmosphere Crystal Grower"

"Diffusion of Sodium in Sodium Chloride in an Applied Electric Field"

"Crystal Field Effects on the Wavefunction and Physical Properties of the F Center in Solids with the NaC1 Structure" "Photoconductivity of $\mathrm{z}_{1}, \mathrm{z}_{2}$, and $\mathrm{z}_{3}$
Centers in $\mathrm{KCl:Sr}$ "

"High Temperature Ionic Conductivity of AgC1" 
(D) Contract Reports

\begin{tabular}{|c|c|}
\hline $\begin{array}{l}\text { CoO-1197- } 4 \\
\text { Mar., } 1963\end{array}$ & R.J. Friauf \\
\hline $\begin{array}{l}\text { C00-1197- } 8 \\
\text { Mar., } 1964\end{array}$ & R.J. Friauf \\
\hline $\begin{array}{l}\text { Coo-1197-14 } \\
\text { Mar., } 1965\end{array}$ & R.J. Friauf \\
\hline $\begin{array}{l}\text { Coo-1197-17 } \\
\text { Mar., } 1966\end{array}$ & $\begin{array}{l}\text { R.J. Friauf } \\
\text { and G.G. Wiseman }\end{array}$ \\
\hline $\begin{array}{l}\text { CoO-1197-23 } \\
\text { Mar. , } 1967\end{array}$ & R.J. Friauf \\
\hline $\begin{array}{l}\text { COO-1197-37 } \\
\text { Sep., } 1968\end{array}$ & R.J. Friauf \\
\hline
\end{tabular}

First Annual Progress Report

Second Annual Progress Report

Third Annual Progress Report

Fourth Annual Progress Report

Fifth Annual Progress Report

Final Report 
LIST OF PERSONNEL

(A) Professiona1

Man-Months
Prof. Robert J. Friauf
Principal Investigator
Prof. Gord on G. Wiseman
Senior Investigator
Dr. Paolo Podini
Research Associate
Total

33

7.2

21

61.2

(B) Graduate Research Assistants

Man-Months

Harold Breed love

5.5

Harry Downing

Donald Foster

Joseph Gracey

Gerald Holmberg

Shih-Pei Hu

2.0

19.5

2.5

5.5

1.0

Soo-Ung Kim

10.0

Juergen Kuebler

7.8

Dennis Lauer

4.0

Robert Mellott

25.0

Vaughn Nelson

27.5

Frederick Pilcher

0.5

David Renneke

18.0

Iyle Taylor

16.0

Lawrence Walsh

5.5

Max Weber

1.0

Total

151.3 